\title{
EMBEDDING CREATIVITY IN ENGINEERING DEGREE PROGRAMMES
}

\author{
Jamie FINLAY and Adam PAPWORTH
}

Liverpool John Moores University, UK

\begin{abstract}
According to Lucas and Hanson [1] in a paper that formed the basis of a report by the Royal Academy of Engineering, engineering education now stifles, and indeed suppresses the creative and innovative capacities of students at a time when the UK Government [2] maintains innovation is key to delivering prosperity. The irony is, of course, that the very meaning of the word "engineer" has its roots in the ancient word "gene" - to invent, bring into being or create.

This problem is possibly being compounded by the UK Department for Education taking its cues from a Chief Scientific Advisor - with a background in economic history - whose views on creativity and the value schools add in that sphere are poles apart from substantial evidence to the contrary. If uncorrected, the course our government is charting may well consign the UK to economic history.

Convinced of the "creativity gap" in higher education, the authors of this paper outline the key principles uncovered following very recent ongoing, small-scale research that shows how innovation and creativity could be embedded in any design or engineering degree programme and how these qualities could not only improve outcomes for graduates, but also the UK's place in the global economy.
\end{abstract}

Keywords: Design, education, engineering, creativity, innovation, economy

\section{INTRODUCTION}

The singular objective of this research was to answer the question: can creative confidence be rekindled in young adults studying an engineering discipline? If so, then there is potential for increased innovation and therefore invigoration of the UK engineering economy.

In early July 2015, the authors developed a plan to re-house the undergraduate Product Design Engineering (PDE) programme within the Department of Electronics and Electrical Engineering - an unusual home for this discipline and challenging the status quo. Part of this plan included a determination to embed creativity, and therefore innovation, firmly at its core.

At the same time as the move into a new department, the PDE programme was redeveloped. One of the newly crafted first-year modules entitled "Design Principles" was to be delivered in the first semester. This module was to be in the vanguard for the creative transformation of the programme and proof positive that creativity could be taught as asserted in so many words by Scott et al [3] "creativity training is effective".

The Design Principles module, using the methods in Sir Ken Robinson's book "Finding Your Element" was designed to support the transition of new students entering the PDE programme. It did so by helping students rediscover their creative confidence, collaborate with each other on a product-orientated challenge quickly developing a strong group identity. The project immersed students in a journey of self-discovery and insight - into not just themselves but the discipline they had chosen to study. This took them along paths of problem finding, innovative play, creativity, experimentation and educated risk taking. The tangible results were an innovative Design Award and their reflections captured by fiveminute video, which was later analysed.

\subsection{Do Schools Really Kill Creativity?}

For the authors, there were no "principles" at this time only the knowledge that the aforementioned module needed to be designed with Sir Ken Robinson's view on the state of the school education system firmly in mind. 
Clearly young undergraduates were beginning their product design journey without the necessary tools to help them achieve their academic and future professional goals, and so the module was built around the following learning outcomes:

1. Identify and reflect upon the following aspects of personal development: strengths and weaknesses, motivations and values, ability to work with others.

2. Apply creative and imaginative approaches in problem solving and the development of designs.

3. Create a concept model through iterative development of aesthetic forms using hand modelling techniques.

Sir Ken Robinson is not alone in claiming schools are killing creativity [4] - this story is, in fact, an old one. Over fifty years ago, in 1968, US scientists and researchers George Land and Beth Jarman [5] used the test they had developed to assess the creativity of engineers and scientists at NASA and, gave it to 1,600 American children in a longitudinal study starting aged 4 and finishing aged 15 years with remarkable results.

The original purpose of the test was to enable NASA to select the most creative, divergent thinkers, to work on the most complex problems facing them at that time. Such was the simplicity of the test, Land and Jarman were curious to know how children might perform. What they discovered was remarkable - $98 \%$ of the children were categorised, according to their test, at genius level for imagination creativity by another name. Expanding on this study Land and Jarman followed the school children through their academic careers and re-tested them at the ages of 10 and 15. The results showed a dramatic decline in those classified 'genius' in respect of imagination. 10-year-olds now had a 30\% 'genius' level of imagination and dropped to just $12 \%$ in 15 year-olds.

The test has since been taken by over 1 million adults, with an average age of 31 , and just $2 \%$ demonstrate genius level imagination. To paraphrase Land [6] "2\% of the population solving $100 \%$ of the world's problems is not a viable approach to the future."

The views of Robinson, Land and Jarman, Lucas and Hanson, are clearly at odds with Chief Scientific Adviser at the UK Department for Education, Tim Leunig [7], who hypothesis that "... creativity is based on knowledge which in turn is based on literacy." In a clear challenge to Robinson's belief that schools are complicit in the decline of creativity, Leunig appears to suggest that schools are, in fact, the key to creativity. If one thinks of Leunig's premise as a series of building blocks, the foundation would be school, and literacy, knowledge and finally creativity would be tiered above it in that order.

This view the current authors feel is not only wrong but, given Leunig's position in the government, a potential threat to the economic future of the country. Although proof that creativity does not depend on literacy is outside of the scope of this conference paper it is hoped the reader can, for themselves, conjure many anecdotal instances of creativity in action that do not require literacy. If what Leunig said is true, then surely homo sapiens would have long since expired as a species, devoid of any ability to think about and tackle a problem. Invention, innovation and creation all have their genesis in creativity - it is the very basis of those words. Eighteen years before Leunig's TEDx talk, Land and Jarman wrote "What we have concluded, is that non-creative behaviour is learned" - the complete antithesis of Leunig's view.

\subsection{A University Challenge}

Whatever the truth about creativity at the primary and secondary levels of education, the truth at the tertiary level - at least according to Genco [8] first year engineering students typically have more creativity and innovation than those of graduates. Higher education is apparently stifling and suppressing the creative and innovative capacities of our young engineers and this is bad news for the economy. The Design Commission [9] were clear: we must nurture innovation in the UK "specifically through [their] strategic use of design."

In order to support the economy effectively, we do, of course, need the support and talents of designers and engineers, but the current authors would argue that, more than their talent we need their fearless, uninhibited creativity, and for that you need confidence. Clearly, tertiary level design and engineering education needs transforming if the UK is to flourish. The current authors believe creativity can be nurtured and taught in the disciplines of design and engineering - even given the paucity of the undergraduate's current state of creativity. 


\section{FINDING YOUR ELEMENT}

The new Design Principles module was introduced to encourage students to exercise their creative muscle, weakened by an educational system that was conceived during the Industrial Revolution to train young boys and girls to be good workers and follow instruction - what Arthur Koestler [10] terms the associative thinking. The tactic taken was to give students the opportunity, encouragement and support to practice their creative skills - their divergent and, what Arthur Koestler called, bisociative thinking processes. The relative success (in terms of student feedback) of the approach encouraged author Adam Papworth (who leads the module) to, in September 2017, continue with the above methods the following academic year.

\subsection{Methodology}

During induction in September 2017, the authors welcomed the new first year cohort onto the Product Design Engineering course and, during one of the sessions, asked them to anonymously answer a series of questions on their views of their own creativity and personal traits. This exercise was done using the MeeToo Microsoft PowerPoint polling add-in and the exercise was repeated with the same group of students in February 2019. In 2017 there were 27 respondents, and this dropped to 24 in 2019. Despite the relatively small sample size and the lack of any control in the data collection process, the results proved encouraging.

During semester one, the new undergraduates were then given the task of creating a Young Designer of the Year Award and, once the physical model was made, to make a 5-minute reflective video on the process, values, motivations and intentions of their design award. Most importantly, students were asked to reflect on and highlight key moments of insight during the creative and critical thinking phases of the design process and how effective the award's design met their original intentions.

A qualitative analysis of the frequency of key words used in the students' video presentations found that they felt the most important aspects of a designer's personality is to be creative and innovative, empathic, emotional intelligent and intrinsically motivated.

In order for students to succeed in this assessment a counterculture that encourages iterative "safe failure" and nurturing creative confidence was set up against a backdrop of an established culture that is goal and marks focused. Despite this being extremely difficult, feedback from students was positive: "Ifeel non-patronised in this module by staff in this area which is excellent as it gives me the confidence to ask anything on my mind that I feel necessary to develop my skills in this module".

\subsection{Results}

As asserted earlier and by Kelley [11], confidence is the key to being a creative practitioner. In order to be imaginative, you must have an environment that is supportive, encouraging and uncritical. What is shown in figure 1 below is a clear indication that confidence appears to be growing as the student cohort progresses from year one into year two. 




Figure 1. PDE Students at Year 1 (27 respondents) and Year 2 (24 respondents)

Figure 2 shows a corresponding increase in how creative students felt they were over the same period with a significant shift at the right-hand tail of the creativity curve. For this question, students were asked to rate their own creativity from zero to ten, with ten being genius level.

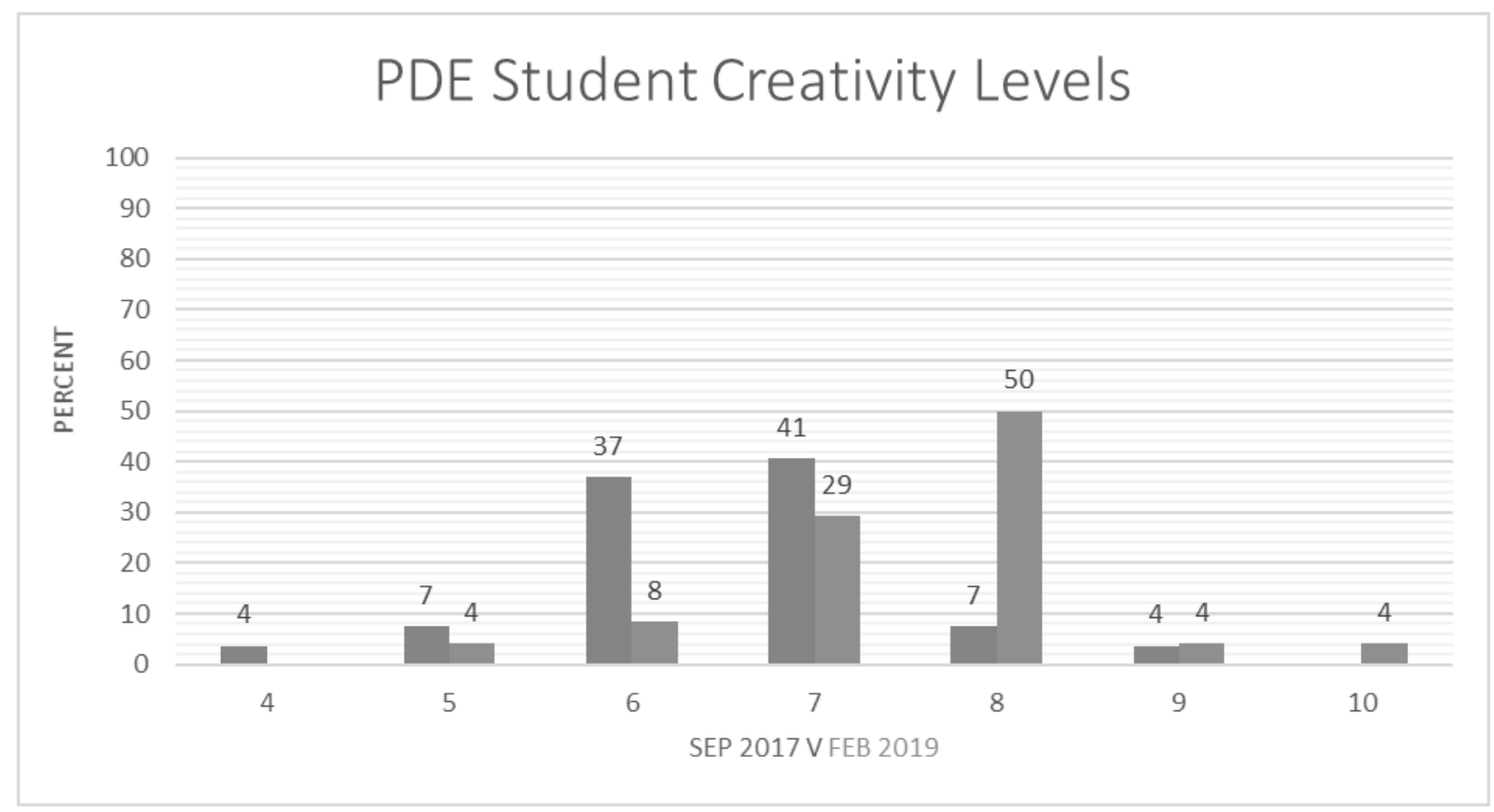

Figure 2. PDE Students at Year 1 (27 respondents) and Year 2 (24 respondents)

When comparing how the course performs against other engineering-based undergraduate programmes (see Figure 3), data has been collected from the UKES - the UK Engagement Survey [12]. In the three years since its inception the programme has performed very well when compared with other engineering disciplines in the institution and with the UKES average for the sector.

In $2018,80 \%$ of the group were in agreement that their overall student experience contributed to their knowledge, skills and personal development in respect of being innovative and creative. This compares to $42 \%$ for mechanical engineering undergraduates and $68 \%$ for all respondents in the sector. 


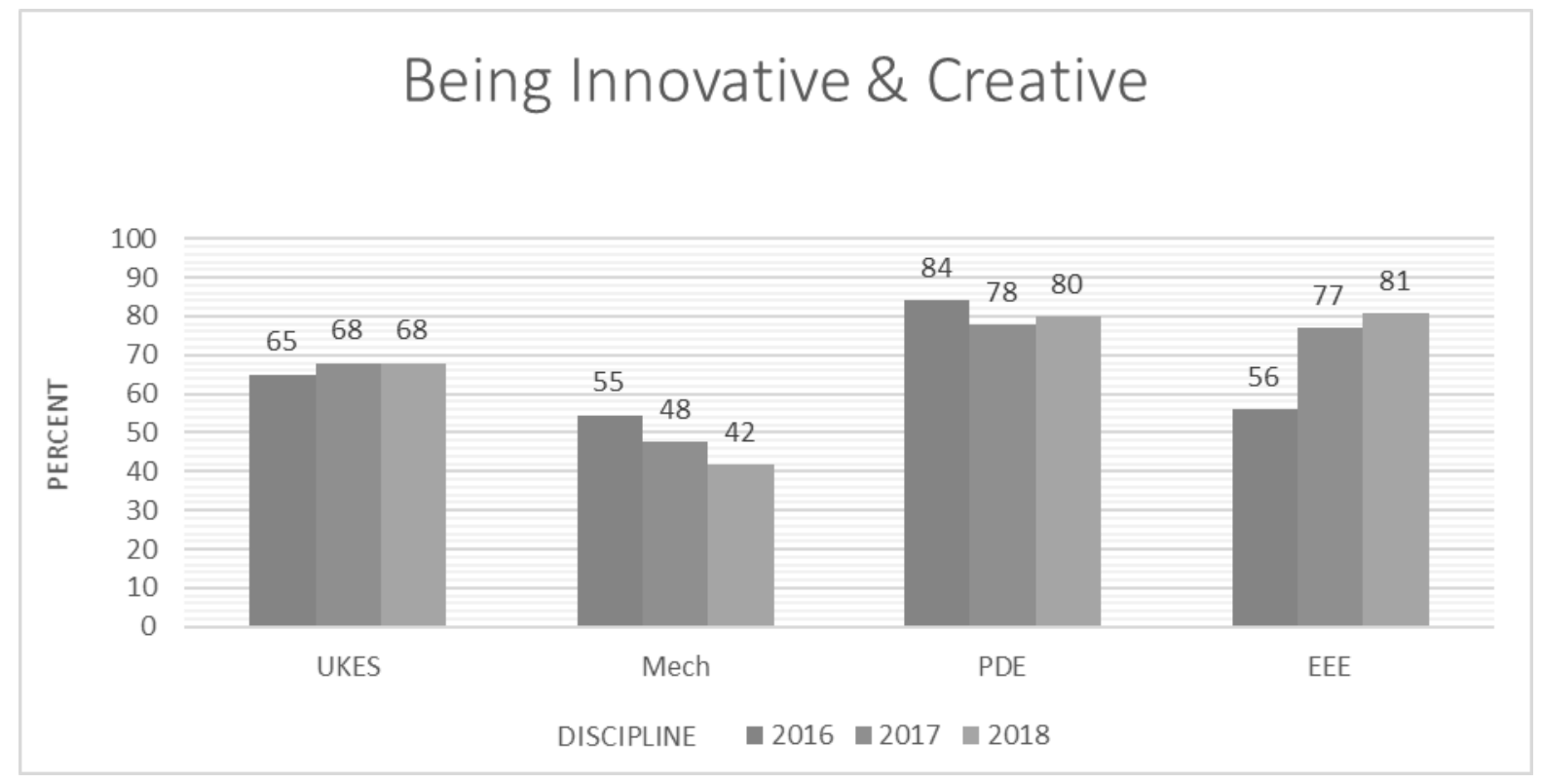

Figure 3. Graduate Data: Students Who Feel Innovative and Creative by Discipline

Table 1. Number of Respondents to UKES by Discipline and Year

EEE MECH PDE UKES

\begin{tabular}{l|cccc}
\hline $\mathbf{2 0 1 6}$ & 16 & 36 & 19 & 23,198 \\
\hline $\mathbf{2 0 1 7}$ & 21 & 31 & 9 & 35,927 \\
$\mathbf{2 0 1 8}$ & 14 & 19 & 5 & 34,635 \\
\hline
\end{tabular}

\subsection{Analysis}

From the results shown in the graphs in the previous section, we can deduce:

1. Over 18 months, fear and anxiety have been largely supplanted by increased confidence, which answers our principle research question: Can creative confidence be rekindled in young adults studying an engineering discipline?

2. Over the same period, mean creative levels of the group rose $10 \%$ to $75 \%$ and a dramatic shift upwards in creativity levels are apparent.

3. The PDE programme has sustained its performance over the past 3 years in respect of how students feel about their own innovative and creative talents, although the data set is rather small when compared to mechanical and electrical engineering disciplines in the university.

In the authors' view the design of the first-year module and assessment was of paramount importance in unlocking first confidence and, subsequently, the creative talent that our students possess. However, there are also hidden factors that cannot be prescribed and are difficult to quantify, such as students' intrinsic motivation and the significance of the role of the module leader in creating a "safe space" in which to work - encouraging and even demanding iterative failure.

On consideration of the work done over the past three years and the results of this small-scale study, the authors have distilled a small number of governing principles that can result in creating a more confident and creative person. A draft of these principles is as follows:

- Prepare to fail. Intrinsic motivation needs to be supplemented by a mentor who will encourage students to take risks in a "safe space". 
- Action trumps passivity. The learning outcomes should be prescriptions for taking action: descriptors should be verbs and knowledge should be applied.

- Collaborate. Teaching delivery should feel more like a collaboration or mentorship than didactic - there should be some sense that the burden of the problem is being shared.

- Empathise - be human. The assessment a problem that is couched in terms of the human factors, necessitating empathic thinking. The output should be a physical solution and also incorporate a reflective piece.

- Diverge then converge. The learning strategy should use both convergent and (mostly) divergent techniques. These builds both confidence and resilience. It should have no small measure of empathic thinking.

\section{CONCLUSIONS}

Is it possible that, as adults, even UK government policymakers no longer have the creative capacity to re-engineer the UK's education system (credible, given just $2 \%$ of adults are classified 'genius' for imagination according to Land and Jarman). However, this should not stop design engineering educators from doing it despite this impediment and succeeding in helping produce confident, creative graduates capable of establishing the UKs position and role in the wider world through the careful crafting of courses that follow the five principles outlined here.

The authors believe that in order to produce confident, creative engineering designers, academics must practice from day one to ensure that students start to build creative confidence. This, we hypothesize, grows as students' progress through years two and three and is what sets Product Design Engineering graduates apart from other engineering disciplines when it comes to these qualities.

At this stage it would be unwise to attempt to draw too much significance from this small-scale study but the authors are encouraged and will be following all new and current students through their course in a much longer study that will, it is hoped, provide more concrete evidence that courses can be designed such that the output is confident, creative engineers with improved outcomes for graduates and the engineering economy.

\section{REFERENCES}

[1] Lucas B. and Hanson J. Thinking Like an Engineer: Using Engineering Habits of Mind and Signature Pedagogies to Redesign Engineering Education. International Journal of Engineering Pedagogy, 2016, Vol. 6, No. 2, $4-13$.

[2] Department for Digital, Culture, Media \& Sport. Creative industries' record contribution to UK economy. Available: https://www.gov.uk/government/news/creative-industries-recordcontribution-to-uk-economy [Accessed 2018, 16 November] (2017) 29 November.

[3] Scott G., Leritz L.E. and Mumford M.D. The Effectiveness of Creativity Training: A Quantitative Review. Creativity Research Journal, 2004, Vol. 16, No. 4, 361-388.

[4] Robinson K. TED 2006 Do Schools Kill Creativity. Available: https://www.ted.com/talks/ken_robinson_says_schools_kill_creativity [Accessed on 2019, 06 March] (2011) 16 February.

[5] Land G. and Jarman B. Breakpoint and Beyond: Mastering the Future Today. Leadership 2000 Inc, August 1, 1998, ISBN 0962660523

[6] Land G. TEDxTucson The Failure of Success. Available: https://www.youtube.com/watch?v=ZfKMq-rYtnc [Accessed on 2019, 06 March] (2011) 16 February.

[7] Leunig T. Why real creativity is based on knowledge. Available: http://bit.ly/TEDx-Leunig [Accessed on 2018, 16 November] (2016) 17 October.

[8] Genco N., Holtta-Otto K. and Seepersad C. An Experimental Investigation of the Innovation Capabilities of undergraduate Engineering Students. Journal of Engineering Education, Vol. 101, No. 1, pp. 60-81.

[9] Design Commission Designing the Digital Economy, 2014.

[10] Koestler A. The Act of Creation Paperback, Hutchinson, 1964.

[11] Kelley D. and Kelley T. Creative Confidence: Unleashing the Creative Potential within Us All, Harper Collins, 2015, ISBN 0008139385

[12] Neves J. 2018 UK Engagement Survey 